\title{
RELATIONSHIP BETWEEN AGE AT FIRST CALVING AND LONGEVITY AND PRODUCTIVE LIFE IN HOLSTEIN COWS
}

\author{
Vladislav Valchev ${ }^{1}$, Ivaylo Marinov², Teodora Angelova ${ }^{3}$ \\ ${ }^{1}$ Faculty of Agriculture, Trakia University, 6000 Stara Zagora, Bulgaria \\ ${ }^{2}$ Department of Animal Husbandry - Ruminants and Dairy Farming, Faculty of Agriculture, Trakia University, \\ 6000 Stara Zagora, Bulgaria \\ ${ }^{3}$ Institute of Agriculture, Stara Zagora, 6000 Stara Zagora, Bulgaria
}

Link to this article: https://doi.org/10.11118/actaun202068050867

Received: 12. 3. 2020, Accepted: 17. 6. 2020

To cite this article: VALCHEV VLADISLAV, MARINOV IVAYLO, ANGELOVA TEODORA. 2020. Relationship Between Age at First Calving and Longevity and Productive Life in Holstein Cows. Acta Universitatis Agriculturae et Silviculturae Mendelianae Brunensis, 68(5): 867-874.

\begin{abstract}
The aim of the study was to evaluate the effect of age at first calving on functional traits - longevity and productive life in dairy cows. The survey included 1490 Holstein cows from 5 cattle farms in Bulgaria. The average milk yield per cow in the farms studied ranged from $6031.68 \mathrm{~kg}$ to $8660.37 \mathrm{~kg}$. The average age at first calving was 29.68 months. The highest percentage of cows calved for the first time at age 28-30 months - 29.53\%, generally 38.06\% of cows calved for the first time at a very high age - over 31 months and only $7.58 \%$ calved aged up to 24 months. The average longevity for all culled cows was 6.05 years and the productive life -3.63 years. $22 \%$ of all culled cows at these farms were culled before the end of their first lactation. The highest total longevity was in cows calved for the first time at high age - over 28 months. Cows calved for the first time, both at low age (up to 24 months) and at high age (over 37 months), had a shorter productive life of 4.0 and 3.9 years, respectively. Cows with the shortest productive life - one year and less - had and the highest average age at first calving of 30.21 months.
\end{abstract}

Keywords: dairy cows, functional traits, AFC, culling rate

\section{INTRODUCTION}

Heifer rearing has an important role in dairy cattle farming. It requires large financial costs, which are usually the second largest after feed costs, and with no return until the animals enter the main herd. Cooke et al. (2013) indicate that an earlier age at first calving (AFC) may reduce rearing costs because of the reduced feed, labor and investment costs.

The effect of the AFC on longevity is not studied well.

A number of studies have shown that age and body weight at calving can have a significant effect on both subsequent milk production (Pirlo et al., 2000) and productive life duration (Ettema and Santos, 2004; Evans et al., 2006), although the results are not always one-way. These differences can be due to variations in genetics and management between different studies and countries. Also, the information on influence of AFC on the survival rate is insufficient, although this trait is becoming increasingly important for the dairy industry (Shook, 2006). Farmers need such information to make informed management decisions about the heifer growth rate and strategies for their farming (Cooke et al., 2013). According to Do et al. (2013) AFC of dairy cows is an indicator that must be properly managed in order to achieve the highest economic return and longer productive live.

Basic approach to reducing the inputs at the beginning can be the reduction of the unproductive period of the heifers, which can be accomplished by 
their earlier conception, to reduce the AFC (Abeni et al., 2000). Krpálková et al. (2014) find that lower AFC does not always lead to the most profitable result for the herd. The local conditions for each farm remain an important factor. Production costs for feed and amortization vary greatly between the farms. Market prices also vary because they follow changes in agricultural markets. According to Meyer et al. (2004) universal recommendations for a particular AFC may be incorrect for all cattle breeds and all farms, as the recommendation may not be consistent with the management goal or the capabilities of a particular production system or farm. Each dairy farm has its own unique set of management and environmental conditions that make universal AFC and body weight a difficult goal to achieve.

The aim of the study was to evaluate the effect of age at first calving on functional traits in Holstein cows housed in Bulgaria.

\section{MATERIALS AND METHODS}

The study included Holstein cows from 5 cattle farms in the Sliven region, under the control of same one breeding association. For convenience of comment and confidentiality regarding the performance traits, farms are presented as a number. The study included data on a total of 1490 cows culled in the period 2010-2018.

Cows in farms 2 and 5 were housed in free stall barns and in the rest - under the conditions of bedded pack housing system. In all farms, the milking was in a milking parlor "Herringbone" type, with number of places corresponding to farm capacity. In all farms replacement heifers were own production. The rearing of female calves and heifers was the same across the five farms. During the preweaning period calves were housed in individual hutches outdoors and during the rest of the periods - they were group housed on deep straw bedding, subject to the requirements for technological sizing of group pens, depending on the age of the animals.

The farms surveyed were located in a region with the same climatic and forage conditions. The feeding of the cows and replacement heifers was based on corn silage, hay and green forage (seasonal) and compound feed. The animals from all farms were not grazed on pasture.

Details of origin, dates of birth, culling, productive traits and other cow information were taken from the breeding association data base from the official records. The average milk yield (kg) for 305 DIM of studied culled cows was calculated on the base of all their finished standard lactations (not shorter than 240 DIM). Cows included in the study were daughters of 266 sires.

The age at first calving was calculated from the date of birth to the date of the first calving. Longevity was calculated as the difference between the date of culling and the date of birth of the cow. Productive life was calculated, respectively - as the difference between the date of culling and the date of first calving

For better approximation in data processing, the age of first calving is represented in classes, respectively:

- 1 - up to 24 months,

- 2 - from 25 to 27 months,

- 3 - from 28 to 30 months,

- 4 - from 31 to 33 months,

- 5 - from 34 to 36 and

- 6 - over 37 months.

To study the relationship between AFC and duration of productive life, it is presented also in classes, respectively:

- 1 - up to 1 year,

- 2 - 1 to 2 years,

- $3-3$ to 4 ,

- 4-5 to 6 and

- $5-7$ and more years.

For the basic statistical processing, the corresponding modules of software packages of MS EXEL and STATISTICA of Stat Soft were used.

To determine the degree of influence of the different factors and to derive reliable models the following model in general was used:

$Y_{i j k}=\mu+H_{i}+Y_{j}+$ Age $_{k}+$ Sire $_{l}+e_{i j k l m}$,

where:

$Y_{i j k m} .$. is the dependent variable (the studied trait);

$\mu$........is the population mean;

$H_{i} \ldots . .$. is the $i^{-h t}$ effect of the herd;

$Y_{j}$.......is the $j^{\text {th }}$ effect of the year of birth;

Age $_{k}$. .is the $k^{\text {th }}$ effect of the age of first calving;

Sire ${ }_{l}$...is the $l^{\text {th }}$ effect of the father;

$e_{i j k} \ldots . . .$. is the effect of the not included random effects, except $\mu$.

By analysis of variances (ANOVA) for each model by classes of fixed factors were evaluated the least squares of means (LSM), calculated as deviation from the mean value of the trait derived from the model.

\section{RESULTS AND DISCUSSION}

The average milk yield for 305 days in milk (DIM) for all culled cows is presented in Tab. I. The average milk yield of cows from the farms surveyed was around and over $6000 \mathrm{~kg}$, only at farm 5 it was significantly higher. The lowest was the average milk yield for cows at farm $3-6031.68 \mathrm{~kg}$, and the highest at farm $5-8660.37 \mathrm{~kg}$. The differences between all farms were statistically significant at $\mathrm{P}<0.05$, except for those between farms 2 and 3 .

The reported average milk yield for the farms studied was above the average for the breed in the country. According to data of the EASRAB (Yordanov et al., 2017), the average milk yield of Black-andwhite breed (Holstein type) cows in Bulgaria is 
5300-5600 kg, with 3.6-3.8\% fat and 3.2-3.3\% protein in milk. As mentioned, the surveyed farms were from a well-developed agricultural region, with good feed and climatic conditions, as well as with highly productive animals.

The average AFC of cows was based on data for all cows that have been culled from 2010 to 2018 and is 29.68 months, Tab. I. AFC varied across the farms. The differences in the average values of AFC between all farms were statistically significant at $\mathrm{P}<0.01$. The lowest AFC was on farms 1 and 4, 28.79 and 28.51 months, respectively, and the highest on farm $5-30.33$ months. The cows on this farm had the highest average milk yield for 305 DIM.

The reported average AFC was much higher than that recommended for Holstein cows. Mourits et al. (2000) indicated that the AFC usually varies between 24 and 36 months and has steadily decreased over the last decade in most countries around the world, with the first calving of around 24 months becoming a common goal. In order to maximize profits, some studies have found that the optimal age of first calving is good to vary between 23 and 24.5 months (Pirlo et al., 2000; Ettema and Santos, 2004). Pietersma et al. (2006) indicated that in the Canadian province of Quebec, the average AFC is traditionally higher than these recommendations, with the average values for Holstein and Ayrshire being 26.5 and 27.1 months, respectively. In Sweden, the average AFC for Holstein cows is 28 months (Wejdmark, 2014). Hammoud et al. (2010) reported that the average AFC for Holstein cows in Egypt is 30.7 months.

In Bulgaria, from the studies of the AFC in the years back in time, it can be said that no change was reported. The reported by Zahariev et al. (1988) average ACF for 3058 high-performance Black-andwhite cows was 882.3 days (29.41 months), and Gergovska and Yordanova (2011) found in 1460 Black-and-white cows calved between 1995 and 2006 an average AFC of 892.1 days or 29.7 months. A lower average age at first calving in Bulgaria was indicated by Penev et al. (2014) in 818 Blackand-white cows from 7 farms - 26.6 months, with varying from 25 to 28 months by farms. Shindarska et al. (2016) pointed significant differences in AFC for two dairy cattle farms, 23 to 29 months respectively for one and 28 to 36 months for the other. The reported differences from the mentioned authors were probably due to differences in management and subjective decisions in the studied farms.

In Fig. 1 is presented the percentage of cows depending on the AFC. The highest was the percentage of cows calved for the first time at the age of 28-30 months - 29.53\%, followed by these calved at younger age of 25 to 27 months $-24.83 \%$. About $62 \%$ of the cows in the studied herds have calved for the first time up to 30 months of age. Unfortunately, 38.06\% have calved for the first time at a very high age - over 31 months. This means that their unproductive life was over 2.5-3 years. Very low percentages of cows have calved on age up to 24 months, only $7.58 \%$.

This tendency for later first calving in Blackand-white cows in Bulgaria has not changed substantially in the last 10 years. The data presented by Gergovska $(2009,2011)$ showed that the first calving among about $34 \%$ of the Black-and-white cows in Bulgaria occurred relatively late - at 2730 months of age, with $22.9 \%$ calving for the first time at 30-33 months.

The reasons for the higher AFC can be sought in two directions. One is subjective decisions of farmers for later conception of the heifers for a number of reasons, one of which is the prejudice to the negative consequences of the early conception of heifers associated with their calving and productivity. Such concerns were also

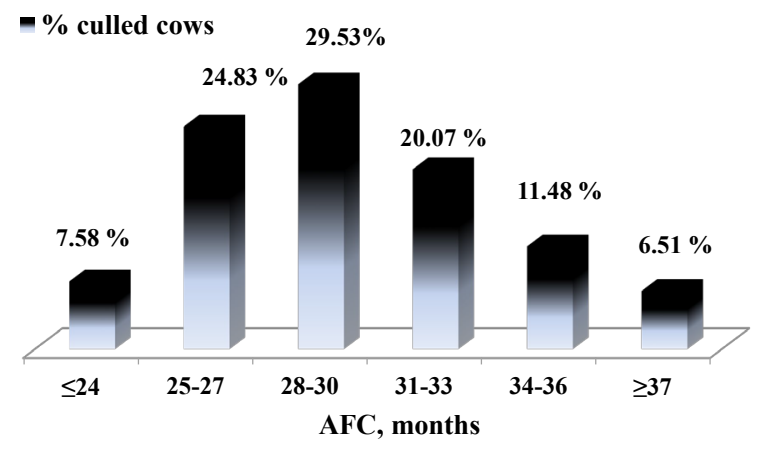

1: Percentage of culled cows depending on AFC

I: Average values and variation for age at first calving and milk yield for 305 DIM of culled cows by farms

\begin{tabular}{|c|c|c|c|c|c|c|}
\hline \multirow{2}{*}{\multicolumn{2}{|c|}{ Farm No. Number of cows }} & \multicolumn{2}{|c|}{ Age at first calving (months) } & \multicolumn{3}{|c|}{ Milk yield for 305 DIM (kg) } \\
\hline & & $\mathrm{x} \pm \mathrm{SE}$ & SD & Number of lactations & $\mathrm{x} \pm \mathrm{SE}$ & SD \\
\hline 1 & 300 & $28.79 \pm 0.25^{a}$ & 4.39 & 716 & $6989.33 \pm 61.43$ & 1643.66 \\
\hline 2 & 165 & $29.71 \pm 0.31^{\mathrm{ab}}$ & 4.03 & 407 & $6131.68 \pm 103.33$ & 2084.63 \\
\hline 3 & 115 & $29.28 \pm 0.35^{c}$ & 3.78 & 153 & $6032.27 \pm 268.09$ & 3316.12 \\
\hline 4 & 154 & $28.51 \pm 0.20^{\mathrm{bcd}}$ & 2.45 & 398 & $6613.14 \pm 73.15$ & 1459.31 \\
\hline 5 & 756 & $30.33 \pm 0.15^{\text {acd }}$ & 4.03 & 1460 & $8660.37 \pm 39.62$ & 1514.10 \\
\hline Total & 1490 & $29.68 \pm 0.10$ & 4.02 & 3134 & $7561.92 \pm 36.53$ & 2045.05 \\
\hline
\end{tabular}

The differences between farms with identical letters are statistically significant at $\mathrm{P}<0.05$ 
II: Average longevity and productive life of culled cows by farms

\begin{tabular}{|c|c|c|c|c|c|}
\hline \multirow{2}{*}{ Farm No. } & \multirow{2}{*}{ Number of cows (n) } & \multicolumn{2}{|c|}{ Longevity (in years) } & \multicolumn{2}{|c|}{ Productive life in herd (in years) } \\
\hline & & $\mathrm{x} \pm \mathrm{SE}$ & SD & $\mathrm{x} \pm \mathrm{SE}$ & SD \\
\hline 1 & 300 & $5.27 \pm 0.10^{\mathrm{abcd}}$ & 1.72 & $2.83 \pm 0.09 \mathrm{abc}$ & 1.54 \\
\hline 2 & 165 & $7.75 \pm 0.25^{\mathrm{ae}}$ & 3.18 & $5.20 \pm 0.25 a$ & 3.18 \\
\hline 3 & 115 & $7.63 \pm 0.25^{\mathrm{bf}}$ & 2.71 & $5.23 \pm 0.26^{\text {bde }}$ & 2.74 \\
\hline 4 & 154 & $7.34 \pm 0.21^{\mathrm{cg}}$ & 2.57 & $4.99 \pm 0.2^{\mathrm{cf}}$ & 2.57 \\
\hline 5 & 756 & $5.57 \pm 0.07^{\text {defg }}$ & 2.02 & $3.07 \pm 0.0^{\text {def }}$ & 2.04 \\
\hline Average & 1490 & $6.09 \pm 0.06$ & 2.44 & $3.63 \pm 0.06$ & 2.43 \\
\hline
\end{tabular}

The differences between farms with identical letters are statistically significant at $\mathrm{P}<0.01$

highlighted by Pirlo et al. (2000) among Italian farmers. The other reason is the neglected feeding and rearing of female calves and heifers, leading to slower reaching the desired live weight and body development for conception. Moreover, indicators related to the development of young animals such as live weight and conformation traits were not controlled on our farms. Popova (2003) pointed out that the practice of relatively late conception of heifers in Bulgaria (aged 16-18 months) was mainly due to inadequate nutrition.

In relation to the allegation of Meyer et al. (2004), that universal recommendations for a particular AFC may be incorrect for all cattle breeds and all farms, can be pointed and the reported by our study highest AFC in cows on a farm 5, which was with the highest capacity, but also with the highest milk yield per cow.

The efficiency of rearing dairy cows is determined, apart from their milk performance level and from length of the time spent in the herd and the total quantity of milk produced, respectively. One of the most commonly used traits for evaluation the cow efficiency is longevity and productive life in herd.

Tab. II shows the average longevity of culled cows (in years) by farms. The average longevity of all cows culled on farms for the study period (1490 cows) was 6.05 years, with significant individual variation ranging from 1.95 to 13.21 years. By farms, the average longevity of culled cows also varied, with differences between the average farm values being statistically significant at $\mathrm{P}<0.01$. The cows from farms 1 and 5 had the lowest average longevity -
5.27 and 5.57 years respectively. These ware also the farms with the highest capacity. For the other three farms there was no significant difference in the average longevity - from 7.34 to 7.75 years.

Overall longevity is not an accurate indicator of the sustainability of animals, as more accurate is assumed the productive life in herd - from the first calving to the date of culling. Tab. II presents the data for the duration of productive life in herd for all culled cows in total and by farms. The average productive life of all cows from the study was 3.63 years, which was a relatively short period - just over 3 lactations. With the shortest productive life, were also the cows from farms 1 and 5, respectively, 2.83 and 3.07 years, in which the shortest longevity was also reported. This equates to about 2 to 3 lactations. In the other three farms, the productive life duration was slightly longer, with small differences ranging from 4.99 to 5.23 years, or about 4-5 lactations. Individual variations in this trait were significant from 0 to 11.07 years. The reported duration indicated by 0 means that the animal was culled after less than 1 month after calving.

Other authors in other countries also reported a relatively short productive life of dairy cows. The average productive life of a Swedish cow was 2 to 2.5 lactations (Carlén, 2013; Carlén and Eriksson, 2013), which means that a cow that had its first calf at the age of 30 months may not be able to pay its rearing costs before culling

From the studied data on culled cows from the five farms was found that 321 cows or 22 percentages were culled before the end of their first lactation.

III: Number and percentage of culled cows on first and third lactation by farms

\begin{tabular}{lccccccc}
\hline \multirow{2}{*}{\multicolumn{1}{c}{ Traits }} & \multicolumn{7}{c}{ Farm No. } \\
\cline { 2 - 7 } & 1 & 2 & 3 & 4 & 5 & Total \\
\hline Number of culled on first lactation & 48 & 23 & 18 & 24 & 199 & 321 \\
\hline \% of the total number of culled & 16.0 & 15.2 & 16.7 & 16 & 26.5 & 22.0 \\
Number of culled before finishing normal lactation & 22 & 6 & 11 & 9 & 46 & 94 \\
\hline \% of the total number of culled & 7.3 & 4.0 & 10.2 & 6.0 & 6.1 & 6.4 \\
\hline \% of cows reached third lactation & 60.3 & 70.9 & 69.6 & 67.5 & 49.2 & 57.5 \\
\hline
\end{tabular}


IV: Analysis of variance for influence of the controlled factors on longevity and productive life

\begin{tabular}{|c|c|c|c|c|c|}
\hline Source of variation & Degrees of freedom $(n-1)$ & MS & F P & MS & F P \\
\hline Farm & 4 & 16.27 & $11.31^{* * *}$ & 15.72 & $11.02 * * *$ \\
\hline Year of birth & 16 & 92.45 & $64.25^{* * *}$ & 91.48 & $64.12^{* * *}$ \\
\hline Sire & 266 & 1.69 & $1.17^{*}$ & 1.68 & $1.18 *$ \\
\hline Error & 1049 & 1.44 & & 1.43 & \\
\hline
\end{tabular}

* - significance at $\mathrm{P}<0.05 ;{ }^{* *}$ - significance at $\mathrm{P}<0.01 ; * *$ - significance at $\mathrm{P}<0.001 ;-$ no significant effect

There was no data on conception of these cows after the first calving, Tab. III. For most farms, the percentage of culled primiparous was about $16 \%$ of the total number of culled cows, with the exception of farm 5, where the number and, respectively, the percentage of these cows was much higher $-26.5 \%$.

Of the presented number of culled primiparous a total of 94 , or $6.4 \%$ of the total number of culled animals have left the herds before reaching a normal lactation (min - 240 days), Tab. III. These animals lacked performance data and did not participate in the breeding evaluation of their sires. Other authors also report a significant number of heifers (14\%-19\%) culled during their first lactation, with poor fertility being a major cause of such high losses in these relatively young animals (Esslemont and Kossaibati, 1997; Brickell and Wathes, 2011). In addition to the premature culling of infertile animals, poor reproductive efficiency increases the number of cows to be inseminated, increases the interval between calvings and reduces the number of calves sold for the year.

Tab. III shows the percentage of cows reached third lactation from the total number of culled animals. These were cows reached full age and probably maximum productivity. The average percentage of cows reached third lactation was $57.5 \%$. This percentage of cows was highest on farms 2 and 3, respectively 70.9 and 69.6\%. The lowest percentage of cows reaching full age was reported on farm $5-49.2 \%$. The results obtained indicated that in farms with higher capacity and higher milk production (farms 1 and 5), about the half of the cows (40-50\%) dropped out of the herds before reaching full age and maximum productivity. In these farms, a high selection culling was reported, especially among primiparous. In the smaller farms and in cows with lower milk yield, about $70 \%$ of cows reached third lactation.

The analysis of variance for the influence of the controlled factors on the two functional traits longevity and productive life (Tab. IV) showed that the effect of the farm and year of birth were of the highest significance $(\mathrm{P}<0.001)$, followed by AFC $(\mathrm{P}<0.01)$ and sire $(\mathrm{P}<0.05)$.
The effect of AFC on longevity is presented in Fig. 2. The mean longevity increased with increasing AFC. The highest was the longevity of cows calved for the first time at a fairly high age over 28 months, ranging by age groups from 7.06 to 7.36 years. The cows calved for the first time at a low age of up to 24 months had the lowest longevity -6.11 years respectively. This confirmed the view that inadequate feeding of young breeding animals leads to insufficient development for conception at an earlier age (14-15 months).

The first calving at an appropriate, mature age, ensures good body health for life, and early calving is detrimental to longevity, as found by Pirlo et al. (2000) and Haworth et al. (2008). Do et al. (2013) indicated that longevity increases linearly with increasing AFC, with further increases in longevity greater than that in AFC. Larger variations in longevity were observed when the first calving occurred before 700 days of age (23 months). Vukasinovic et al. (2001) found a curvilinear effect of AFC, slightly increased risk of culling cows that calved very early and especially increased risk in calved very late.

Greater interest in relation to efficiency of farming dairy cows was the trait duration of productive life. Fig. 2 presents LS-means for productive life duration depending on the AFC. Cows calved for the first time, both at low age (up to 24 months) and at high age (over 37 months), had a shorter productive

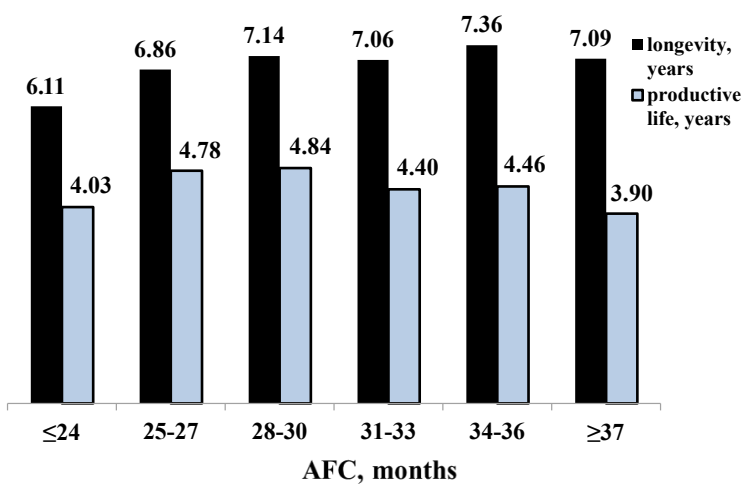

2: LS-means for longevity and productive life depending on AFC 


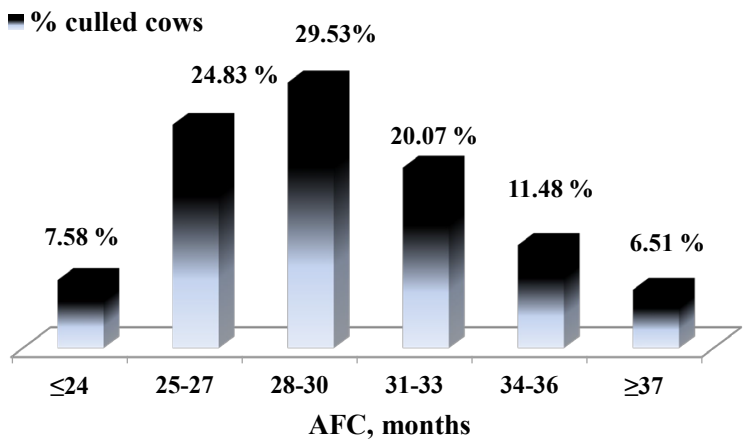

3: ACF (in months) at different duration of productive life (in years)

The differences between the groups indicated by identical letters were statistically significant at $\mathrm{P}<0.05$

life, respectively 4.0 and 3.9 years. With the longest productive life were cows calved for the first time at the age of 25-27 months and at 28-30 months -4.78 and 4.84 years. The difference between the means for the shortest and longest productive lives was about 1 year, but economically speaking, this is milk yield for one lactation and a calf more. In cows, calved for the first time at a very late age - over 37 months, half the total duration of life was unproductive.

Fig. 3 shows the inverse relationship, which presents the average AFC of cows, depending on duration of their productive life. The figure clearly indicates that the cows with the shortest productive life - one and less years - also had the highest average AFC of 30.21 months.
Although with a small difference of about 1 month, the average AFC of cows with the longest productive life (7 years and over) was the lowest - 29.01 months, the difference being statistically significant. The results showed that cows with high AFC had a higher risk of culling at an early age at the first lactation. M'hamdi et al. (2010) observed a linear increase in the relative risk of culling proportionally to the increase in AFC with a risk equal to " 1 " for 27 months AFC. Chirinos et al. (2007) found the highest risk of culling of cows with AFC over 34 months. Bielfeldt et al. (2006) also reported a higher risk of culling if the first calving occurs when the heifers are over 3 years old.

When comparing the effect of AFC on the two functional traits, it was clear that the higher longevity in cows with later AFC was due to the prolonged unproductive part of life - until first calving.

The results showed that increasing the AFC had a positive effect on productive life and milk income (Do et al., 2013). Mészáros et al. (2008) did not find a large effect of AFC on the longevity of dairy cows.

Evans et al. (2006) indicate that when the AFC increases beyond 30 months, the time to first calving or the unproductive life of cows becomes longer than the average productive life. In addition, cows with an AFC of more than 30 months have more reproductive problems, lower milk yield and less milk fat, and are generally more at risk of culling and with shorter productive lives.

\section{CONCLUSION}

The average AFC of the cows included in the study (29.63 months) was quite high compared to the recommended for the breed, with significant variation by farms. The highest percentage of cows have calved for the first time at age 28-30 months - 29.53\%, generally 38.06\% have calved for the first time at a very high age - over 31 months. Very low percentage of cows have calved aged up to 24 months, only 7.58\%. In Bulgaria, as in some other countries, farmers do not control the growth and development of replacement heifers. Conception decisions were most often made subjectively, with the lower age of conception being avoided because of fear of reproductive problems.

The average longevity of all culled cows in the farms for the study period was 6.05 years and the productive life was 3.63 years, which was just over 3 lactations. The average longevity increased with increasing the age at first calving. The highest total longevity was in cows calved for the first time at a fairly high age - over 28 months.

Cows calved for the first time, both at low age (up to 24 months) and at high (over 37 months), had a shorter productive life of 4.0 and 3.9 years, respectively. For cows calved for the first time at a very late age - over 37 months, half of the total longevity was unproductive. The cows with the shortest productive life - one and less years - had and the highest average AFC of 30.21 months. The results showed that cows with high AFC had a higher risk of culling at an early age - during the first lactation. It is necessary to change the negative attitude of farmers to the earlier age of conception of heifers (with control of growth and development), which will lead to better results in terms of their duration of use.

\section{REFERENCES}

ABENI, F., CALAMARI, L., STEFANINI, L. and PIRLO, G. 2000. Effects of daily gain in pre- and postpubertal replacement dairy heifers on body condition score, body size, metabolic profile, and future milk production. Journal of Dairy Science, 83(7): 1468-1478. 
BIELFELDT, J. C., TOLLE, K. H., BADERTSCHER, R. and KRIETER, J. 2006. Longevity of Swiss Brown cattle in different housing systems in Switzerland. Livestock Science, 101(1): 134-141.

BRICKELL, J. S. and WATHES, D. C. 2011. A descriptive study of the survival of Holstein-Friesian heifers through to third calving on English dairy farms. Journal of Dairy Science, 94(4): 1831-1838.

CARLÉN, E., ERIKSSON, J.-Å. and SVERIGE, V. 2013. Kornas livslängd - hur påverkas gardens resultat? Presentation from Djurhälso- och ut-fodringskonferensen 2013 conferency. Available at: https:// docplayer.se/2168368-Kornas-livslangd-hur-paverkas-gardens-resultat.html [Accessed: 2020, July 15].

CHIRINOS, Z., CARABANO, M. J. and HERNÁNDEZ, D. 2007. Genetic evaluation of length of productive life in the Spanish Holstein-Friesian population: model validation and genetic estimation. Livestock Science, 106(2): 120-131.

COOKE, J. S., CHENG, Z., BOURNE, N. E. and WATHES, D. C. 2013. Association between growth rates, age at first calving and subsequent fertility, milk production and survival in Holstein-Friesian heifers. Open Journal of Animal Sciences, 3(1): 1-12.

DO, C., WASANA, N., CHO, K., CHOI, Y., CHOI, T., PARK, B. and LEE, D. 2013. The Effect of Age at First Calving and Calving Interval on Productive Life and Lifetime Profit in Korean Holsteins. Asian Australasian Journal of Animal Science, 26(11): 1511-1517.

ESSLEMONT, R. J. and KOSSAIBATI, M. A. 1997. The cost of respiratory diseases in dairy heifer calves. The Bovine Practitioner, 33: 174-178.

ETTEMA, J. F. and SANTOS, J. E. P. 2004. Impact of age at calving on lactation, reproduction, health, and income in first-parity Holsteins on commercial farms. Journal of Dairy Science, 87(8): 27302742.

EVANS, R. D., WALLACE, M., GARRICK, D. J., DILLON, P., BERRY, D. P. and OLORI, V. 2006. Effects of calving age, breed fraction and month of calving on calving interval and survival across parities in Irish spring-calving dairy cows. Livestock Science, 100(2-3): 216-230.

GERGOVSKA, Z. 2011. Effect of the age at first calving on test day production traits in black-and-white cows. Agricultural Science and Technology, 3(2): 67-72.

GERGOVSKA, Z. and YORDANOVA, L. 2011. Effect of the age at first calving on the evaluation of breeding potential of dairy cattle and its correlation to test day productivity. Agricultural Science and Technology, 3(1): 3-7.

GERGOVSKA, G. 2009. Effect of age at first calving on test day production traits for 305 days lactation in black-and white cows. In: $5^{\text {th }}$ Balkan conference of Animal Science BALNIMALCOL. 14-16 May, 2009.

HAWORTH, G. M., TRANTER, W. P., CHUCK, J. N., CHENG, Z. and WATHES, D. C. 2008. Relationships between age at first calving and first lactation milk yield, and lifetime productivity and longevity in dairy cows. The Veterinary Record, 162(20): 643-647.

KRPÁLKOVÁ, L., CABRERA, V. E., KVAPILÍK, J., BURDYCH, J. and CRUMP, P. 2014. Associations between age at first calving, rearing average daily weight gain, herd milk yield and dairy herd production, reproduction, and profitability. Journal of Dairy Science, 97(10): 6573-6582.

M'HAMDI, N., ALOULOU, R., BRAR, S. K., BOUALLEGUE, M. and BEN HAMOUDA, M. 2010. Study on functional longevity of Tunisian Holstein dairy cattle using a Weibull proportional hazard model. Livestock Science, 132(1-3): 173-176.

MÉSZÁROS, G., WOLF, J. and KADLEČÍK, O. 2008. Factors affecting the functional length of productive life in Slovak Pinzgau cows. Czech Journal of Animal Science, 53: 91-97.

MEYER, M. J., EVERETT, R. W. and VAN AMBURGH, M. E. 2004. Reduced age at first calving: effects on lifetime production, longevity, and profitability. Kansas Agricultural Experiment Station Research Reports, 0(2): 42-52.

MOURITS, M. C. M., VAN DER FELS-KLERX, H., HUIRNE, R. B. M. and HUYBEN, M. W. C. 2000. Dairyheifer management in the Netherlands. Preventive Veterinary Medicine, 46(3): 197-208.

PENEV, T., VASILEV, N., STANKOV, K., MITEV, J. and KIROV, V. 2014. Impact of heifers' age at first breeding and first calving on some parameters of economic effectiveness at dairy cattle farms. International Journal of Current Microbiology and Applied Sciences, 3(11): 772-778.

PIETERSMA, D., LACROIX, R., LEFEBVRE, D., CUE, R. and WADE, K. M. 2006. Trends in growth and age at first calving for Holstein and Ayrshire heifers in Quebec. Canadian Journal of Animal Science, 86(3): 325-336.

PIRLO, G., MIGLIOR, F. and SPERONI, M. 2000. Effect of age at first calving on production traits and on difference between milk yield returns and rearing costs in Italian Holsteins. Journal of Dairy Science, 83(3): 603-608.

POPOVA, Y. 2003. Economic effectiveness of rearing own female calves and heifers at dairy cattle farms. Bulgarian Journal of Animal Husbandry, 40: 5-7.

SHOOK, G. E. 2006. Major advances in determining appropriate selection goals. Journal of Dairy Science, 89(4): 1349-1361. 
VUKASINOVIC, N., MOLL, J. and CASANOVA, L. 2001. Implementation of a routine genetic evaluation for longevity based on survival analysis techniques in dairy cattle populations in Switzerland. Journal of Dairy Science, 84(9): 2073-2080.

YORDANOV, G., VENEV, I., PEEVA, J. S., RAYCHEV, E., NIKOLOVA, L. et al. 2017. Lifestock breeds in Republic of Bulgaria. Executive Agency of Selection and Reproduction in Animal Breeding. Sofia, Bulgaria.

Contact information

Vladislav Valchev: vlado88.1988@abv.bg

Ivaylo Marinov: marinov.ib@abv.bg

Teodora Angelova: teslacow@abv.bg 